\title{
Cardiac involvement in rheumatoid arthritis
}

\section{An echocardiographic study}

\author{
P. A. BACON* AND D. G. GIBSON† \\ From the Departments of Rheumatology and Cardiology, St. Bartholomew's Hospital, London E.C.I
}

Pericardial involvement in chronic rheumatoid arthritis (RA) was described by Charcot (1881). Rheumatoid pericarditis has since become an accepted entity, and recently Kirk and Cosh (1969) have shown that careful clinical investigation will reveal its presence in 10 per cent. of patients with chronic RA during life. The post mortem incidence is even higher, ranging from 11 per cent. (Fingerman and Andrus, 1943) to 50 per cent. (Young and Schwedel, 1944) in different series. A less common aspect of cardiac involvement is the development of rheumatoid granulomata involving the heart as first described by Baggenstoss and Rosenberg (1943); in such cases the lesion has only been revealed post mortem.

The development of echocardiography has introduced a harmless 'non-invasive' technique for assessing the position and movements of viscera, including the heart, so that it has become a diagnostic tool of considerable value. It has been used both to detect pericardial effusions (Feigenbaum, 1970) and to measure the movement of the anterior cusp of the mitral valve (Edler, 1967). We have used this technique to investigate, during life, the incidence of both pericardial involvement and altered mitral valve movement in patients with rheumatoid arthritis.

\section{Methods}

A series of 22 patients with classical or definite RA with palpable subcutaneous nodules was compared with a further 22 patients fulfilling the same diagnostic criteria but having no detectable nodules. The majority of patients were examined during routine follow-up at the Rheumatology Clinic although a few were seen during in-patient admissions because of a flare-up of disease activity or for planned surgery. The duration of symptoms was noted and the presence of any other systemic manifestations of rheumatoid arthritis was sought.

A control group of age-matched patients with noninflammatory osteoarticular pathology attending the orthopaedic department was also examined. Any patient with a history of rheumatic fever or obvious signs of rheumatic valve disease was excluded from the series.

An echocardiogram was obtained by standard techniques using an Ekoline 20 ultrasonoscope with simultaneous ECG tracing and a permanent record was made by photographing the sweep on polaroid film. The presence of a pericardial effusion, shown by separation of the anterior or posterior ventricular wall from adjacent thoracic structures, was sought in all cases. The diastolic closure rate of the mitral valve was measured whenever an adequate tracing could be obtained.

\section{Results}

A pericardial effusion was demonstrated in eleven (50 per cent.) of the patients with nodular RA and

Table I Findings in patients and controls

\begin{tabular}{|c|c|c|c|c|}
\hline \multirow[t]{2}{*}{ Group } & & \multicolumn{2}{|c|}{ Rheumatoid arthritis } & \multirow{2}{*}{$\begin{array}{l}\text { Control } \\
\text { (osteoarthrosis) }\end{array}$} \\
\hline & & Nodular & Non-nodular & \\
\hline No. of subjects & & 22 & 22 & 22 \\
\hline Age (yrs) & $\begin{array}{l}\text { Mean } \\
\text { Range }\end{array}$ & $\begin{array}{l}54 \cdot 2 \\
(31-74)\end{array}$ & $\begin{array}{l}51 \cdot 2 \\
(20-72)\end{array}$ & $\begin{array}{l}54 \cdot 9 \\
(34-69)\end{array}$ \\
\hline Duration of disease & $\begin{array}{l}\text { Mean } \\
\text { Range }\end{array}$ & $\begin{array}{l}12 \cdot 5 \\
(1-28)\end{array}$ & $\begin{array}{l}8 \cdot 7 \\
(0 \cdot 5-30)\end{array}$ & - \\
\hline Pericardial effusion & $\begin{array}{l}\text { No. } \\
\text { Per cent. }\end{array}$ & $\begin{array}{l}11 \\
50\end{array}$ & $\begin{array}{r}4 \\
18\end{array}$ & 0 \\
\hline
\end{tabular}


in four (18 per cent.) of the non-nodular patients, but in none of the controls (Table I). The overall incidence in the 44 patients with RA was thus 34 per cent. The effusions demonstrated were chiefly posterior to the heart (Fig. 1), but were occasionally anterior. The majority were small although a few were 1 to $2 \mathrm{~cm}$. in depth. None of these patients had symptoms of pericardial involvement at the time, although one had had typical pain 2 years previously, and none had signs of constriction. Although the nodular patients had had their arthritis for a longer period than the other group, no correlation could be seen between effusion and duration of disease. The majority of effusions were seen in patients whose history was short, but they were also detected in cases of long-standing disease including one of 28 years' duration. Similarly, no correlation could be demonstrated between indices of disease activity, such as haemoglobin and erythrocyte sedimentation rate, and the presence of an effusion.

The mitral diastolic closure rate in the three groups of patients is shown in Fig. 2. The average for the control group is $116 \mathrm{~mm}$./sec. (range 75 to $180)$; this is in keeping with other authors who have taken a figure over $80 \mathrm{~mm}$./sec. as the normal (Edler, 1967; Gibson, 1973). The non-nodular RA group showed a mean rate of $94 \mathrm{~mm}$./sec. (range 40 to 200) with only four patients showing a rate below normal. In contrast, the mean rate for the nodular RA group was $63 \mathrm{~mm}$. $/ \mathrm{sec}$., which is significantly lower than the control $(\mathrm{P}<0.001)$ or the non-nodular RA group $(P<0.05)$. Indeed, only five of the nodular RA patients showed a rate within the normal range. Three patients showed a markedly slow rate, less than $30 \mathrm{~mm}$. $/ \mathrm{sec}$., which is within the range normally associated with significant rheumatic mitral stenosis. No adequate tracing could be obtained from six of

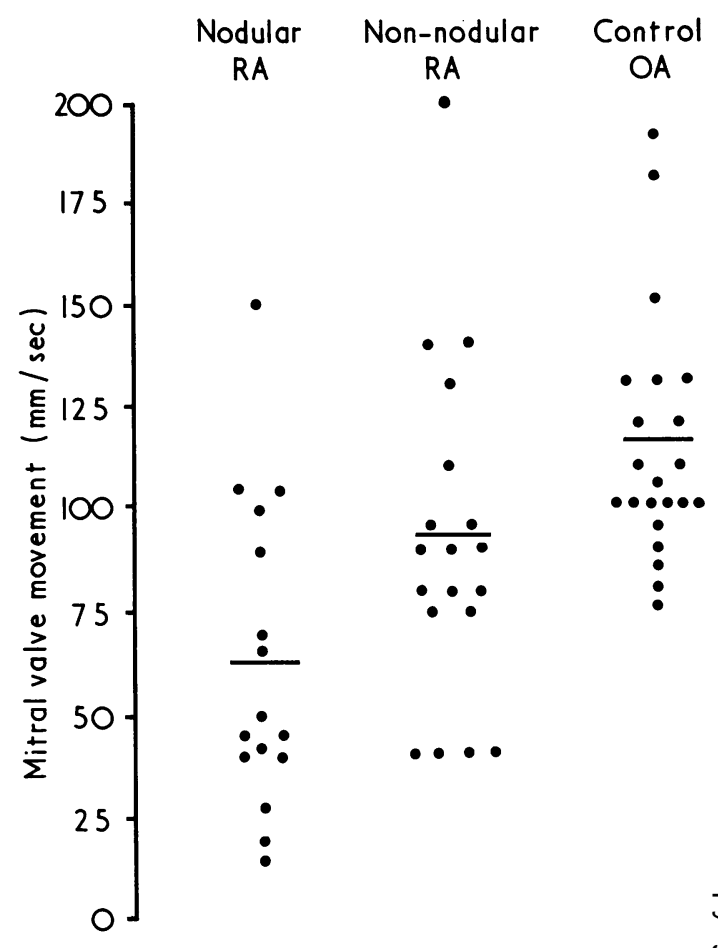

FIG. 2 Mitral valve movement for $R A$ and control groups. Heavy bar represents mean rate for each group

the nodular group or from three of the non-nodular group. Examples of the mitral valve tracings are shown in Fig. 3.

A diminished rate of mitral valve movement was seen with increasing age in the rheumatoid patients $(r=0.328 ; \mathrm{P}<0.05)$ (Fig. 4), which was not apparent

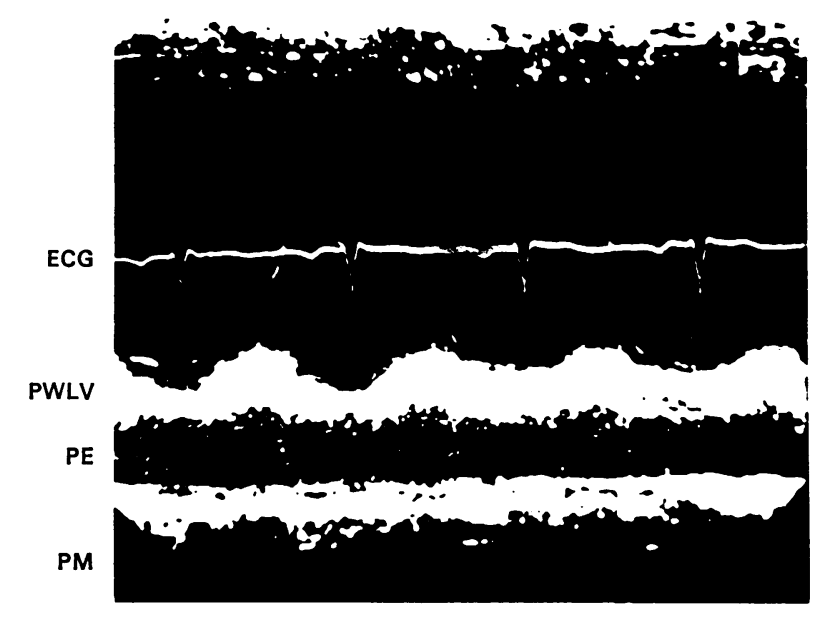

FIG. 1 Pericardial effusion posterior to left ventricle. The effusion is approximately $1.5 \mathrm{~cm}$. across. In this, and subsequent records, the top of the picture represents the anterior chest wall, and the depth markers distances of $1 \mathrm{~cm}$. The left ventricular wall is recognized by its characteristic anterior movement immediately after the $Q R S$ complex on the ECG $P W L V=$ Posterior wall left ventricle $P E=$ Pericardial effusion $P M=$ Posterior mediasternum 

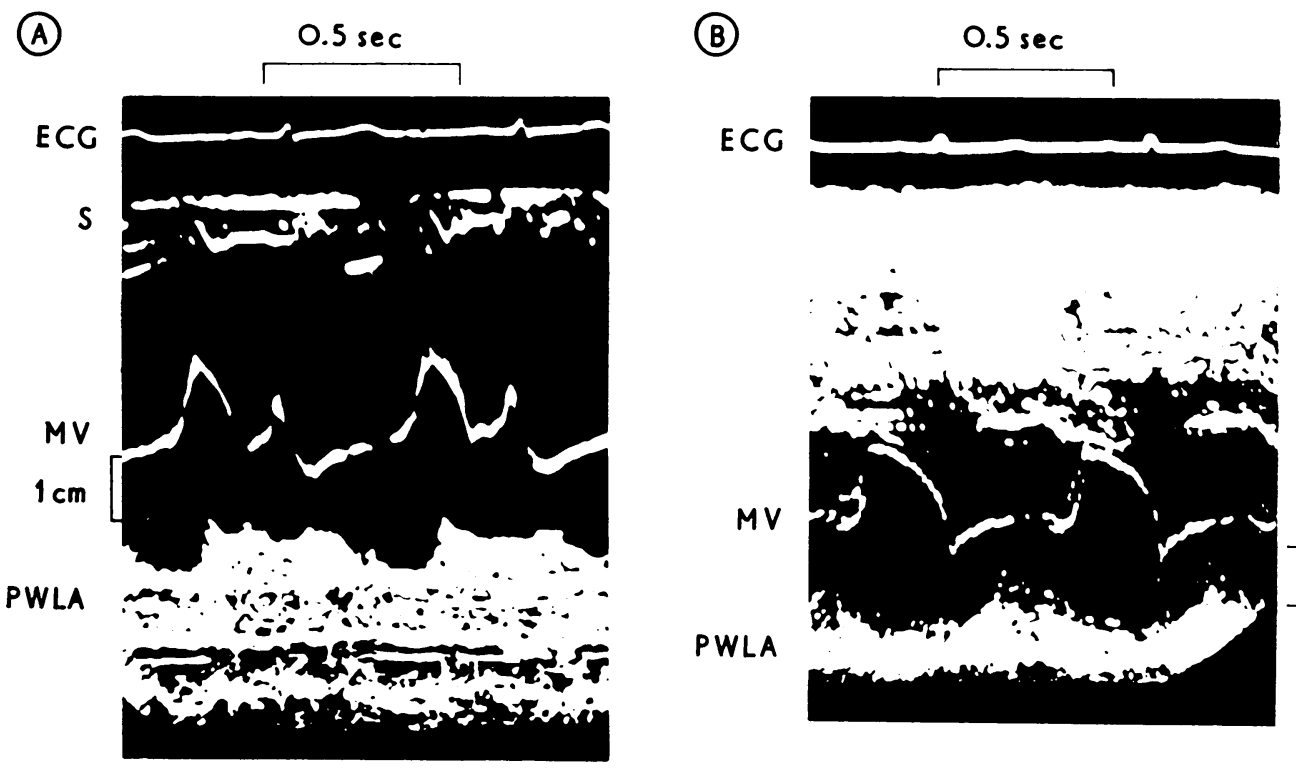

PWLA
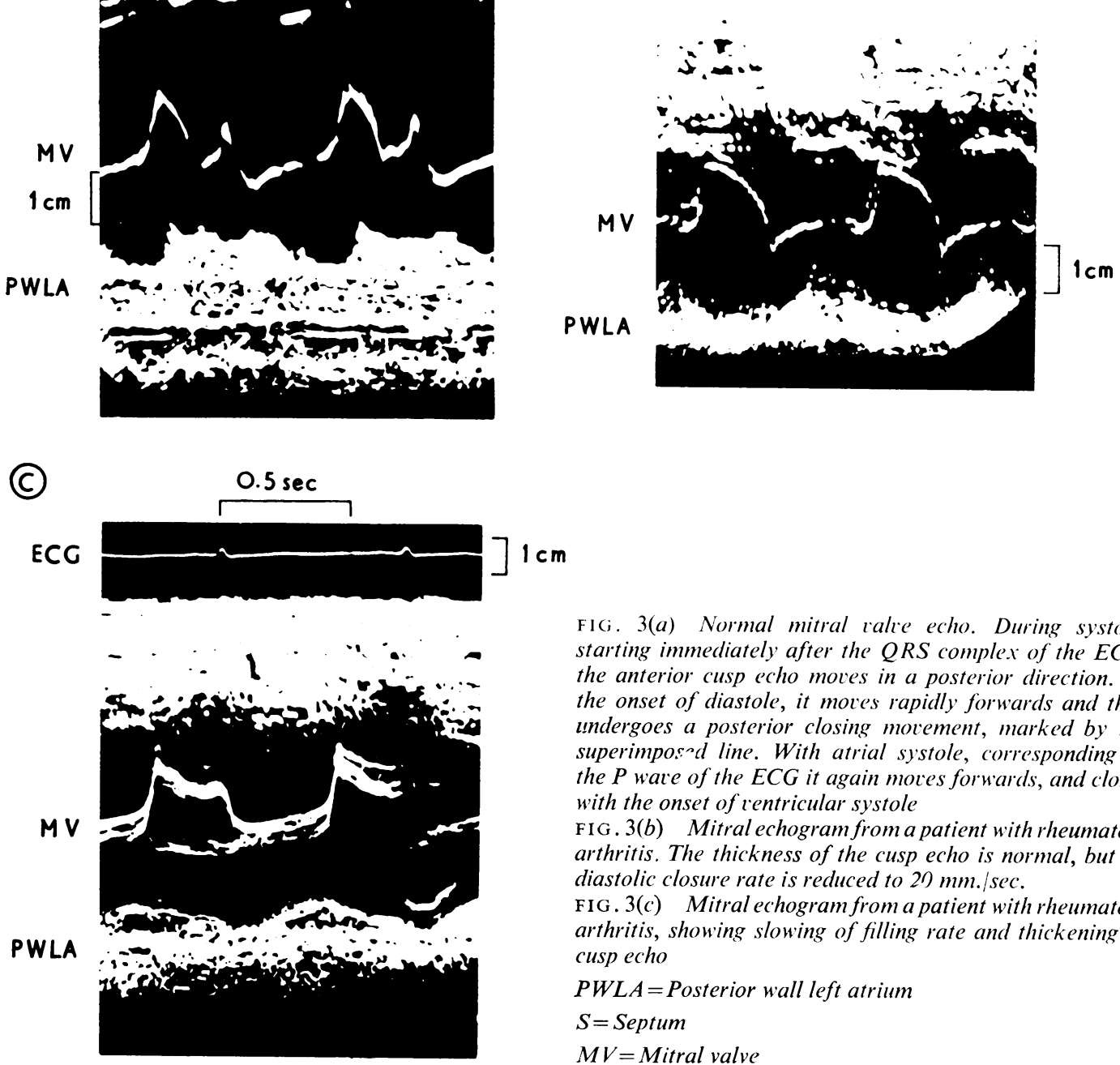

FIG. 3(a) Normal mitral valie echo. During systole, starting immediately after the QRS complex of the ECG, the anterior cusp echo moves in a posterior direction. At the onset of diastole, it moves rapidly forwards and then undergoes a posterior closing movement, marked by the superimposnd line. With atrial systole, corresponding to the $P$ wave of the ECG it again moves forwards, and closes with the onset of ventricular systole

FIG. 3(b) Mitral echogram from a patient with rheumatoid arthritis. The thickness of the cusp echo is normal, but its diastolic closure rate is reduced to $20 \mathrm{~mm}$. $/ \mathrm{sec}$.

FIG. 3(c) Mitral echogram from a patient with rheumatoid arthritis, showing slowing of filling rate and thickening of cusp echo

$P W L A=$ Posterior wall left atrium

$S=$ Septum

$M V=$ Mitral valve

in the controls. A closer correlation was seen with increasing duration of disease $(r=-0.588 ; \mathrm{P}<0.001)$ (Fig. 5). The three very slow rates were seen in nodular patients who had had their disease for 8 , 16 , and 25 years respectively. There was no apparent correlation between the rate of initial valve movement and current disease activity as assessed either clinically or by $\mathrm{Hb}$ or erythrocyte sedimentation rate. However, there appeared to be a connection with overall disease severity. The nodular patients, with the slower mean rate of valve movement, had more severe disease as assessed by incapacity, destructive radiological changes, and the incidence of other systemic manifestations of rheumatoid disease. The incidence of the latter in the two groups is shown in Table II. Apart from the higher incidence of pericardial effusions already noted, other complications of rheumatoid disease were seen in eight of the nodular group and only one of the non-nodular group. The three very slow rates were seen in two patients with Sjögren's syndrome and one with Felty's syndrome. All the patients with complicated rheumatoid disease had slow rates where a record was obtained, except the one patient with rheumatoid pleurisy who had acute disease of only 2 years' duration. 


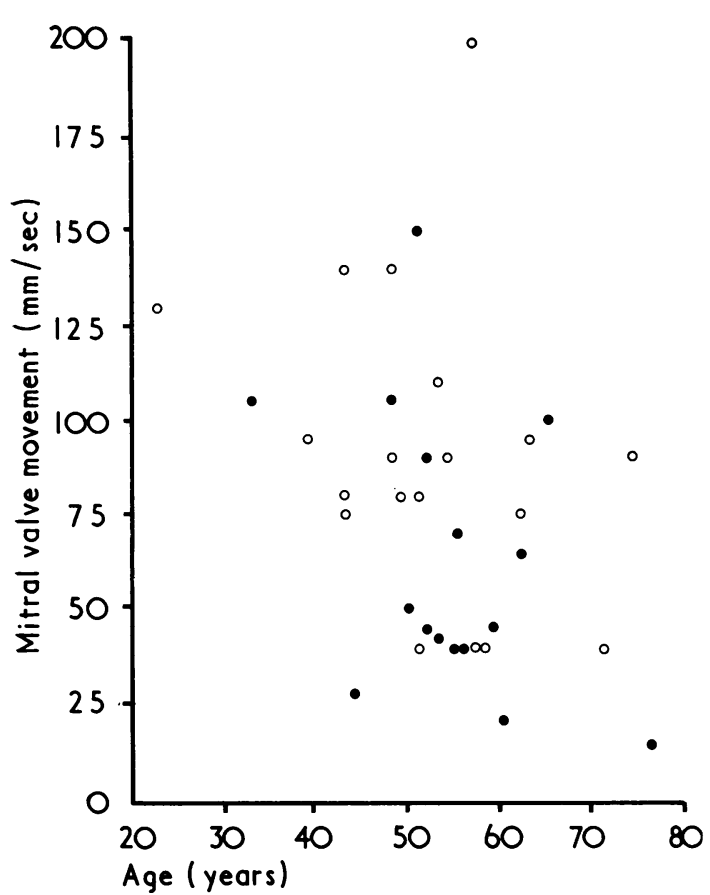

FIG. 4 The relationship between age and mitral valve diastolic closure rate in patients with nodular (O) and non-nodular (O) $R A$. The control group, with osteoarthrosis, showed no diminished rate with age and are not included

Table II Associated systemic disease

\begin{tabular}{|c|c|c|}
\hline Rheumatoid arthritis & Nodular & Non-nodular \\
\hline Pericardial effusion (per cent.) & 50 & 18 \\
\hline $\begin{array}{l}\text { Rheumatoid pleurisy } \\
\text { Fibrosing alveolitis } \\
\text { Felty's syndrome } \\
\text { Pyoderma gangrenosum }\end{array}$ & $\begin{array}{r}150 \\
45 \\
20 \\
\text { N.R. }\end{array}$ & $\begin{array}{l}- \\
-\end{array}$ \\
\hline Sjögren's syndrome & $\begin{array}{c}15 \\
40 \\
28 \\
\text { N.R. }\end{array}$ & 40 \\
\hline
\end{tabular}

\section{Discussion}

Echocardiography provides a simple technique for assessing some aspects of cardiac function. It has revealed a high incidence of clinically unsuspected heart disease in this study of rheumatoid patients. The incidence of pericardial effusion demonstrated during life is considerably higher than that revealed by careful and repeated clinical examination (Kirk and Cosh, 1969). In the nodular group the incidence is similar to the highest reported post mortem figure (Young and Schwedel, 1944). The overall incidence of 34 per cent. in this series is close to the average of 30 per cent. derived by pooling the incidence in

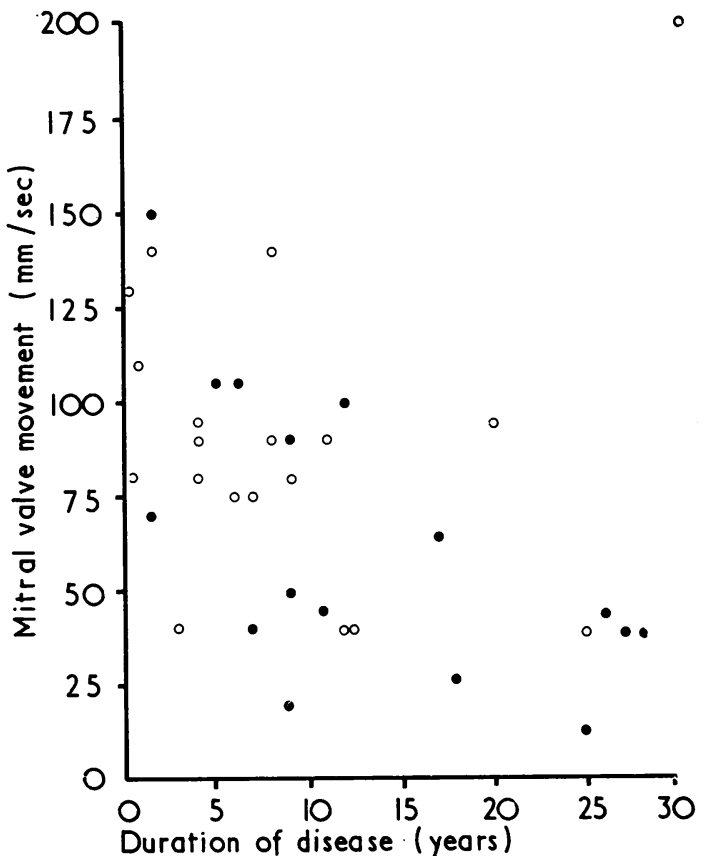

FIG. 5 An inverse correlation is present between diseas\& duration and mitral diastolic closure rate in both nodula (O) and non-nodular (O) patients $(r=0.59 ; P<0.001)$

eight post mortem series totalling over 400 patients (see Kirk and Cosh, 1969). It is probable that this technique detects virtually any pericardial effusion present although it will not reveal old adhesions in the absence of fluid. The fact that fluid could not be detected both anteriorly and posteriorly may be related to the small volume of many of the effusions, but also suggests that in some cases the fluid may be loculated, as has been shown at operation (Kennedy, Partridge, and Matthews, 1966). The paucity of clinical signs or electrocardiographic changes of pericardial effusion is in keeping with the findings of other series (Kirk and Cosh, 1969; Goslings, 1958). The latter may be related in part to the posterior location of the fluid, but also suggests that these are chiefly bland effusions with little of the epicardial involvement which is the chief factor producing electrocardiographic changes in pericarditis.

The recording of a diminished rate of spontaneous mitral valve movement during the mid-diastolic partial closure period is a new observation. The correlation with duration of disease, with severe nodular disease, and with other complications of rheumatoid disease, suggest that this represents a true systemic manifestation of rheumatoid arthritis. The mechanism of the slowing may depend on one or both of two factors: left ventricular disease or intrinsic mitral valve disorder. The generalized slowing seen to an extent in both rheumatoid groups 
may be related to myocardial disease producing a raised end diastolic pressure, as has been demonstrated with other causes of abnormal left ventricular function (Shah, Gramiak, Kramer, and Yu, 1969). An increased incidence of left ventricular hypertrophy and of congestive cardiac failure in RA has been noted by some authors (Sinclair and Cruickshank,1956; Cathcart and Spodick, 1962).

The very slow rate seen in three patients with severe complicated nodular arthritis may be simply an extension of this process, but the figures of 15 to 30 suggest intrinsic mitral valve disease. It is possible that this represents the presence of rheumatoid granulomata involving the mitral valve cusp. The incidence of these endocardial granulomata was 5 per cent. in one large post mortem series (Cruickshank, 1958), although we have only been able to trace 25 cases in the English literature. These were all documented post mortem and were not diagnosed during life although flow murmurs had occasionally been noted. In virtually all cases, the mitral valve was involved, either predominantly or alone, although involvement of all the other valves, the mitral valve ring, and the myocardium has been described (Carpenter, Golden, and Roberts, 1967). The patients described with endocardial granulomata had long- standing severe disease with subcutaneous nodules and other evidence of systemic involvement, very similar to the patients described here. Further clinico-pathological correlation is necessary but it is possible that echocardiography offers the chance to diagnose rheumatoid endocardial granulomata during life.

\section{Summary}

The technique of echocardiography has been used to assess two aspects of cardiac involvement in a series of 44 patients with rheumatoid arthritis (RA), compared with matched osteoarticular controls. A pericardial effusion was demonstrated in 34 per cent. of RA patients and in 50 per cent. of the subgroup with subcutaneous nodules. This is higher than previous clinical estimates, but agrees with post mortem findings. A slowing of mitral valve movement, not previously reported, was also detected in the RA patients. This correlated with nodular disease and with other systemic manifestations of RA. Three patients with nodular RA had very slow mitral valve movement and it is suggested that this represents granulomata involving the mitral valve.

\section{References}

Baggenstoss, A. M., AND Rosenberg, E. F. (1943) Arch. Path., 35, 503 (Visceral lesions associated with chronic infections)

CARPENTER, D. F., Golden, A., AND RoberTs, W. C. (1967) Amer. J. Med., 43, 922 (Quadrivalvular rheumatoid heart disease associated with left bundle branch block)

CathCART, E. S., AND SPODICK, D. H. (1962) New Engl. J. Med., 266, 959 (Rheumatoid heart disease)

CHARCOT, J. M. (1881) 'Visceral affections in acute and chronic articular rheumatism' in 'Clinical Lectures on Senile and Chronic Diseases', p. 164. New Sydenham Society [vol. 95], London.

Cruickshank, B. (1958) J. Path. Bact., 76, 223 (Heart lesions in rheumatoid disease)

EDLER, I. (1967) Amer. J. Cardiol., 19, 18 (Ultrasound cardiography in mitral valve stenosis)

FeIGENBAUM, H. (1970) Ibid., 26, 475 (Echocardiographic diagnosis of pericardial effusion)

FINGERMAN, D. L., AND ANDRUS, F. C. (1943) Ann. rheum. Dis., 3, 168 (Visceral lesions associated with rheumatoid arthritis)

Gibson, D. (1973) 'Echocardiography' in 'Recent Advances in Cardiology', 6th ed., ed. J. Hamer, p. 266. Livingstone, Edinburgh

GosLings, J. (1958) Ann. rheum. Dis., 17, 337 (Pericarditis and rheumatoid arthritis)

Kennedy, W. P. U., Partridge, R. E. H., and Matthews, M. B. (1966) Brit. Heart J., 28, 602 (Rheumatoid pericarditis with cardiac failure treated by pericardectomy)

KIRK, J., AND CosH, J. (1969) Quart. J. Med., 38, 397 (The pericarditis of rheumatoid arthritis)

Shah, P. M., Gramiak, R., Kramer, D. H., and YU, P. N. (1968) New Engl. J. Med., 278, 753 (Determinants of atrial $\left(\mathbf{S}_{4}\right)$ and ventricular $\left(\mathbf{S}_{3}\right)$ gallop sounds in primary myocardial disease)

Sinclair, R. J. G., AND Cruickshank, B. (1956) Quart. J. Med., 25, 313 (A clinical and pathological study of sixteen cases of rheumatoid arthritis with extensive visceral involvement)

Young, D., AND SChWedel, J. B. (1944) Amer. Heart J., 28, 1 (The heart in rheumatoid arthritis. A study of 38 autopsy cases) 